\title{
Mapping a Strength-Oriented Approach to a Standardized Terminology: A Case Study
}

\author{
Grace GAO ${ }^{\mathrm{a}, 1}$, Robin R AUSTIN ${ }^{\mathrm{b}}$, Laura N KIRK ${ }^{\mathrm{b}}$, Diane E HOLLAND ${ }^{\mathrm{c}}$, \\ Candice BRUHJELL ${ }^{\mathrm{a}}$ and Karen A MONSEN ${ }^{\mathrm{b}}$ \\ ${ }^{a}$ Department of Nursing, St. Catherine University, St. Paul, Minnesota, USA \\ ${ }^{\mathrm{b}}$ School of Nursing, University of Minnesota, Minneapolis, Minnesota, USA \\ ${ }^{\mathrm{c}}$ Mayo Clinic, Rochester, Minnesota, USA
}

\begin{abstract}
As a new era of healthcare advocates a more valuable and intelligent approach to care management and delivery based on values and outcomes, shifts toward risk management to boost performance should be considered that encompass the capitalization of health assets or health strengths. To make full use of individuals' or populations' health assets, data capture and representation are needed. This paper uses a strengths-oriented case study mapped to an inter-disciplinary standardized terminology, the Omaha System, to illustrate and compare the conventional problem-based approach to care management with the strengths-oriented approach to care that demonstrates whole-person data capture of an individual's health and health assets leveraged to promote health values and performance. The Omaha system provides a standardized framework to organize the concepts of all of health from a whole-person perspective for documentation to enable data analysis, interoperability, and health information exchange.
\end{abstract}

Keywords. Strengths, problems, strength-based care, problem-based care, the Omaha System

\section{Introduction}

As a new era of healthcare advocates a more intelligent approach to care management and delivery based on values, risk management to generate value-based healthcare solutions [1] call for capitalization of person-centered and population-oriented health assets that maximize health and minimize costs associated with diseases and conditions. The inception of problem lists as the center of patient records in electronic health records (EHRs) to construct a system of healthcare solutions proposed by Dr. Lawrence Weed in the late 1960s, [2] however, still dictates current healthcare practice and documentation in the US. In this problem-oriented healthcare infrastructure, problems, often defined by a problem list, presents negative aspects of data capture of an individual's health, and negates person-centered strengths perceivable as health assets.

Our literature search suggests that leveraging the use of an individual's strengths dated back in the tradition of a holistic nursing care process in the 1980s when a nursing diagnosis of a whole person was constructed upon not only problems but also positive strengths under all problems. [3] When taking on a patient-centered care approach, both

${ }^{1}$ Corresponding Author, Grace Gao, Department of Nursing, St. Catherine University, 2004 Randolph Avenue, St. Paul, MN 55105, USA; E-mail: ggao912@stkate.edu. 
strengths and vulnerabilities of individuals and populations needed to be considered and made visible in data capture. [4] Strengths are health assets embedded across three core cognitive, emotional, and physical dimensions ${ }^{[5]}$ and characterized by skills, capacities, talents, and potential in an individual/family, a healthcare team/member, and community. $[5,6]$ A strengths-based approach is a whole-person patient-centered intervention that leverages patient strengths to assist patients, families, and care teams with managing multiple chronic conditions and support emotional as well as physical well-being. [6,7] A whole-person perspective is an approach to care that addresses a person's needs and treats the disease including both psychosocial needs and physical symptoms. [8,9].

By using the standardized interface terminology, the Omaha System, studies have examined whole-person data capture in nursing care and documentation on both individual and community levels. It was found feasible to use the Omaha System to classify and quantify strengths and needs of older adults with chronic conditions [10,11] and to capture community levels of observations. [12] A strengths perspective was incorporated to analyze nurses' use of evidence-based strength interventions in care coordination for community-dwelling elders [13] and nursing care assessments and interventions. [14,15]

The purpose of this paper is to use a strengths-oriented case study mapped to the Omaha System to illustrate and compare the conventional problem-based approach to care management with the strengths-oriented approach to care that demonstrates wholeperson data capture of an individual's health as well as health assets leveraged to promote health values and performance. The Omaha System is selected for the mapping as it is an inter-professional interface terminology and is accessible to multi-disciplinary healthcare team members.

\section{Methods}

The Omaha System consists of three components including the Problem Classification Scheme, the Intervention Scheme, and the Problem Rating Scale for Outcomes. [16] The Problem Classification Scheme describes all of health in 42 Problem terms/concepts within 4 holistic domains and offers both a structured problem list and standardized vocabulary to capture problem-specific strengths and signs/symptoms. The Problem Rating Scale for Outcomes consists of scales for assessing problem or strength in three dimensions: Knowledge, Behavior, and Status (KBS) using a Likert-type ordinal rating scale from 1 (lowest) to 5 (highest). The Intervention Scheme describes interventions that address a Problem, using an action (Category term in 4 categories) and object of the action (Target term in 75 targets). Each intervention consists of linked ProblemCategory-Target terms, with a care description that is customizable.

We mapped an earliest strengths-oriented case study originally published in 1979 [17] we found in the literature to the Omaha System (Table 1). This case study described the care of 68-year-old female patient's numerous medical problems, the conservative care she received, and the emerging new problems following problem-based treatments and interventions. This patient's problems could not be alleviated until a strength-based approach was adopted in her care. This strength-oriented care enabled her to identify her strengths, adopt a positive outlook, build a positive relationship, and incorporate her strengths and a positive perspective/relationship to address her problems. After finding ways to use her strengths, she was able to effectively manage her medical problems and emotional challenges. 
Table1. Problems and strengths mappings to the Omaha System.

\begin{tabular}{|c|c|c|c|c|c|}
\hline Problems & Domain & Problem & Category & Target & $\begin{array}{c}\text { Behavior } \\
\text { Rating }\end{array}$ \\
\hline Problems & Psychological & $\begin{array}{l}\text { Interpersonal } \\
\text { relationship, Mental } \\
\text { health }\end{array}$ & Surveillance & $\begin{array}{l}\text { interaction, coping } \\
\text { skills, signs/symptoms - } \\
\text { mental/emotional }\end{array}$ & $<3$ \\
\hline Problems & Physiological & $\begin{array}{l}\text { Vision, Circulation, } \\
\text { Neuro-musculo- } \\
\text { skeletal function, } \\
\text { Skin, Pain, } \\
\text { Communicable/ } \\
\text { infectious condition }\end{array}$ & $\begin{array}{l}\text { Treatments \& } \\
\text { Procedures, } \\
\text { Surveillance }\end{array}$ & $\begin{array}{l}\text { signs/symptoms- } \\
\text { physical, medical/dental } \\
\text { care, medication } \\
\text { administration }\end{array}$ & \\
\hline Problems & $\begin{array}{l}\text { Health-related } \\
\text { Behaviors }\end{array}$ & Nutrition & $\begin{array}{l}\text { Treatments \& } \\
\text { Procedures }\end{array}$ & $\begin{array}{l}\text { medication } \\
\text { administration }\end{array}$ & \\
\hline Strengths & Domain & Problem_ST & Category_ST & Target_ST & $\begin{array}{c}\text { Behavior } \\
\text { Rating }\end{array}$ \\
\hline Strengths & Psychological & $\begin{array}{l}\text { Interpersonal } \\
\text { relationship, Mental } \\
\text { health }\end{array}$ & $\begin{array}{l}\text { Teaching, } \\
\text { Guidance, \& } \\
\text { Counseling } \\
\end{array}$ & $\begin{array}{l}\text { interaction, behavior } \\
\text { modification }\end{array}$ & $>4$ \\
\hline Strengths & Physiological & Pain & $\begin{array}{l}\text { Teaching, } \\
\text { Guidance, \& } \\
\text { Counseling } \\
\end{array}$ & stimulation/ nurturance & \\
\hline Strengths & $\begin{array}{l}\text { Health-related } \\
\text { Behaviors }\end{array}$ & $\begin{array}{l}\text { Health care } \\
\text { supervision }\end{array}$ & $\begin{array}{l}\text { Teaching, } \\
\text { Guidance, \& } \\
\text { Counseling, } \\
\text { Surveillance }\end{array}$ & $\begin{array}{l}\text { anatomy/physiology, } \\
\text { sickness/injury care }\end{array}$ & \\
\hline
\end{tabular}

\section{Results}

According to the mappings, the patient's medical problems mainly resided in the Physiological domain (Figure 1). However, the patient's medical problems affect other domains and cascade a series of events and responses beyond the physiological dimension. Such responses create a rippling effect surrounding her health and hinder her positive response and recovery as demonstrated in the associated Behavior ratings of $<3$ (Table 1), indicative of signs/symptoms related to her physiological problems. The Mental health and Interpersonal relationship problems as represented in the Psychosocial domain shows the patient's negative health response to her medical problems and treatments. The Nutrition problem in the Health-related Behavior domain also related to a physiological origin. This problem-based approach generated related interventions mostly in the Physiological domain as evidenced through the intervention string of Problem-Category-Target (Figure 1).

Compared with the problem-focused interventions, the strengths-oriented approach showed the intervention strings of Problem-Category-Target across all three dimensions (Figure 1). The strength-oriented approach afterwards introduced the patient's strengths - the positive spectrum of her health that expanded the decreased Physiological domain to the increased Psychosocial and Health-related Behaviors domains. These strengths- oriented problem terms represented the patient's health assets that were capitalized by the healthcare team to enhance her health and improve her conditions. The associated Behavior ratings of $>4$ showed her improved health outcomes (Table 1) by leveraging the use of her health assets - her strengths. 


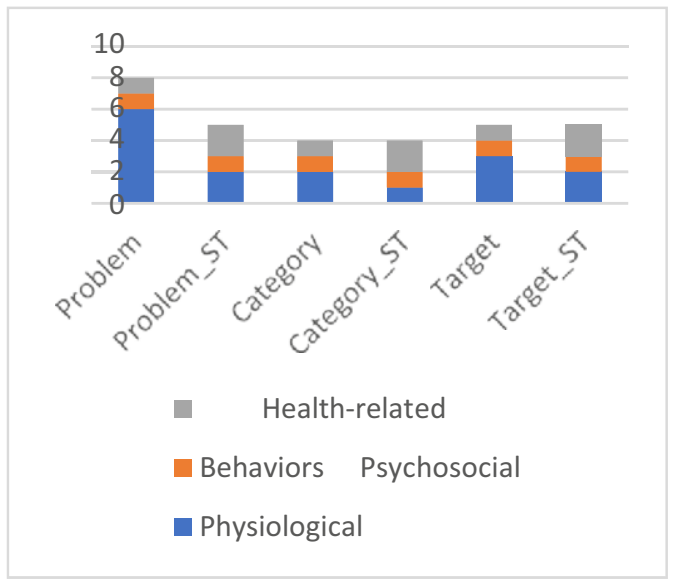

Figure 1. Problem-based care during hospitalization based on domains.

\section{Discussion}

The biomedical model addresses mainly the physiological condition of the patient and lacks the representation of her mental health strengths and challenges. The physiological challenges can impact the patient's other dimensions of health, which contribute to a whole-person approach that includes strengths to move the patient to a better state of health with a better outcome. The strengths-oriented approach constructs the interventions through the patient's strengths, her positive relationship-building, and perspectives to address the physiological challenges and other resulted health challenges not of physiological nature.

The problem term Mental health is used to describe both the patient's problem and strengths. Mental health in the Psychological domain can impact the Physiological domain and vice versa. At the beginning, Mental health was strengths as evidenced by the patient's positive attitude and leveraging of this to help with challenges. As the patient faced significant health decline, mental health was affected and became a problem that impacted her health recovery. Noticing the changes in Mental health from strengths to problems, the healthcare team provided the patient mental health services and support to address it. After receiving support and therapy the patient was able to return the Mental health problems to strengths. This shift signifies the importance of whole-person assessment over time to improve health outcomes by incorporating a strengths-approach to turn health assets into values and better health outcomes.

As shown in this case study, most of the patient's strengths are related to the Psychosocial and Health-related Behaviors domains and a majority of the challenges are associated with the Physiological domain. This is important to identify as the strengths may help to offset the challenges. These findings are consistent with previous studies $[10,11,14,15]$ and are in alignment with the Institute of Medicine's recommendation to capture measures pertaining to the social and psychological domains $[18,19]$ in electronic health records. This type of framework provides the ability to identify individuals' strengths that is not currently part of the patient record. Strengths are used to help with challenges, for example, an individual who has strengths of communication with community resources may be more likely to reach out for services for health challenges. 


\section{Conclusion}

Health data that chronicle whole-person narration of an individual's health story should consist of not only problems but also strengths - the health assets that could be capitalized to enhance health. The Omaha system provides a standardized framework to organize the concepts of all of health from a whole-person perspective for documentation. The Omaha System was mapped to other standardized terminology, for example, SNOMED CT $\AA$, so it can be interoperable with other terminologies that describe problem lists in EHRs to enable data capture, data analysis, interoperability, and health information exchange.

\section{References}

[1] Gentry S, Badrinath P. Defining health in the era of value-based care: Lessons from England of relevance to other health systems. Cureus 9 (2017), e1079.

[2] Weed LL. Medical records that guide and teach. New Engl J Med 278 (1968), $652 \mathrm{e} 7$.

[3] Popkess SA. (1981). Diganosing your patient's strengths. Nursing, 11 (1981), 34-7.

[4] Kotoulas S, Sedlazek W, Lopez V et al. Enabling person-centric care using linked data technologies. In Studies in Health Technology and Informatics, 2014. https://doi.org/10.3233/978-1-61499-432-9-692

[5] Rotegård AK, Ruland CM, Fagermoen MS. Nurse perceptions and experiences of patient health assets in oncology care: A qualitative study. Res Theor Nurs Pract 25 (2011): 284-301.

[6] Miles P, Brunes EJ, Osher TW, Walker JS, National Wraparound Initiative Advisory Group. The Wraparound Process User's Guide a Handbook for Families. Portland, OR, 2016.

[7] Bodenheimer T. Coordinating care: A major (unreimbursed) task of primary care. Ann Intern Med 147 (2007), 730-731.

[8] Zollman C, Walther A, Seers HE, Jolliffe RC, Polley MJ. Integrative whole-person oncology care in the UK. J Natl Cancer Inst - Monogr 2017;2017:26-8. doi:10.1093/jncimonographs/lgx002

[9] Carter J, Zawalski S, Sminkey PV, Christopherson B. Assessing the whole-person: Case managers take a holistic approach to physical and mental health. Prof Case Manag, 20 (2015), 140-6.

[10] Monsen KA, Peters J, Schlesner S, Vanderboom CE, Holland DE. The gap in Big Data: Getting to wellbeing, strengths, and a whole person perspective. Global Advances in Health and Medicine, 4 (2015), 31-39.

[11] Monsen KA, Holland DE, Fung-Houger PW, Vanderboom CE. Seeing the whole person: Feasibility of using the Omaha System to describe strengths of older adults with chronic illness. Res Theor Nurs Pract, 28 (2014). https://doi.org/10.1891/1541-6577.28/4/299

[12] Gao G, Kerr MJ, Monsen KA. Feasibility of describing wellbeing and strengths at the community level utilizing the Omaha System. In: Sermeus W, Procter PM and Weber P, eds. Studies in Health Technology and Informatics: Nursing Informatics. Amsterdam, Netherlands: IOS Press; 2016: 1062-3.

[13] Monsen KA, Vanderboom CE, Olson KS, Larson ME, Holland DE. Care coordination from a strengths perspective: A practice-based evidence evaluation of evidence-based practice. Res Theor Nurs Pract, 31 (2017). https://doi.org/10.1891/1541-6577.31.1.39

[14] Gao G, Kerr M, Lindquist R, Chi C, Mathiason MA, Monsen KA. Discovering associations among older adults' characteristics and planned nursing interventions using electronic health record data. Res Theor Nurs Pract, 33 (2019), 58-80. doi: 10.1891/1541-6577.33.1.58

[15] Gao G, Pieczkiewicz D, Kerr M et al. Exploring older adults' strengths, problems, and wellbeing using de-identified electronic health record data. AMIA Annual Symposium Proceedings.v.2018. (2018). 1263-1272. PMCID: PMC6371293. PMID: 30815168

[16] Martin K. The Omaha system: A key to practice. Documentation and Information Management 2nd Ed. St. Louis, MO: Elsevier Saunders, 2005.

[17] Wiley L (ed.). Nursing grand rounds: finding-and using-your patient's strengths. Nursing, 9 (1979), 405 .

[18] Institute of Medicine. Capturing social and behavioral domains in electronic health records: Phase 1. Washington, DC: The National Academies Press, 2014.

[19] Institute of Medicine. Capturing social and behavioral domains and measures in electronic health records: Phase 2. Washington, DC: The National Academies Press, 2014. 